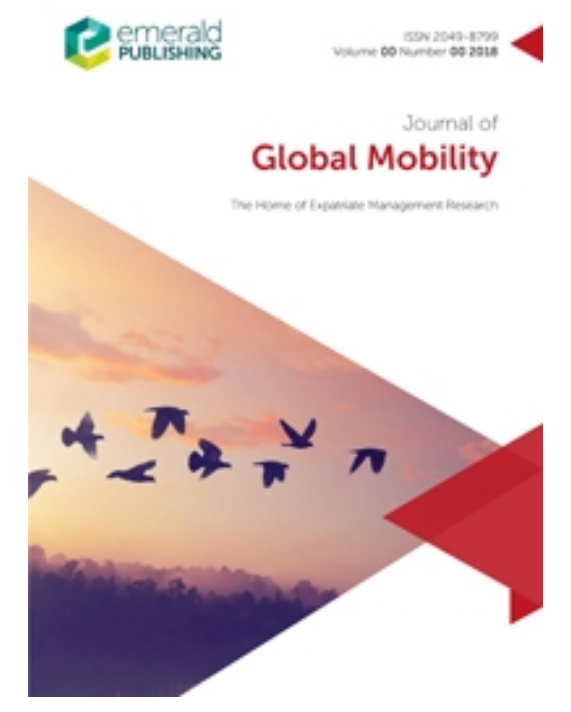

\title{
EXPATRIATE TIME TO PROFICIENCY: INDIVIDUAL ANTECEDENTS AND THE MODERATING EFFECT OF HOME COUNTRY
}

\begin{tabular}{|r|l|}
\hline Journal: & Journal of Global Mobility \\
\hline Manuscript ID & JGM-12-2018-0060.R3 \\
\hline Manuscript Type: & Research Paper \\
\hline Keywords: & $\begin{array}{l}\text { expatriation, Time to proficiency, international experience, culture, } \\
\text { context, adjustment, individual, antecedents, home country }\end{array}$ \\
\hline
\end{tabular}

\section{SCHOLARONE ${ }^{\text {M }}$ \\ Manuscripts}

(c) Emerald Publishing Limited

Waxin, M., Brewster, C. and Ashill, N. (2019), "Expatriate time to proficiency: individual antecedents and the moderating effect of home country", Journal of Global Mobility, Vol. 7 No. 3, pp. 300-318.

https://doi.org/10.1108/JGM-12-2018-0060 


\title{
EXPATRIATE TIME TO PROFICIENCY: INDIVIDUAL ANTECEDENTS AND THE MODERATING EFFECT OF HOME COUNTRY
}

\begin{abstract}
Purpose: This study examines: 1) the direct impact of individual variables (cultural openness, social orientation, willingness to communicate, confidence in own technical abilities, active stress resistance, prior international experience) on expatriate time to proficiency; and 2) the moderating effects of the home country on the relationships between these individual variables and expatriate time to proficiency.

Methodology. We use a quantitative, self-administered questionnaire to gather data from assigned expatriates from different countries in India, analysed through partial least squares.

Findings. The findings show first, that four individual variables, i.e. social orientation, willingness to communicate, confidence in technical abilities and active stress resistance reduce expatriate time to proficiency in the global sample. Second, the individual antecedents of expatriate time to proficiency vary significantly across home countries.

Theoretical implications. Our results confirm the importance of individual antecedents in explaining expatriate time to proficiency and the importance of context in the study of expatriates' cross-cultural effectiveness. We also propose new, shorter measures for the individual antecedents. Practical implications. The practical implications for HRM professionals relate mainly to selection and cross-cultural training. Expatriates may also get a better understanding of the individual and contextual variables that impact their time to proficiency.

Originality/ Value. We show that individual antecedents interact with context, here home country, to predict expatriate time to proficiency in an under-researched host country, India.
\end{abstract}




\begin{abstract}
Key words: expatriation, time to proficiency, adjustment, individual characteristics, international experience, culture, context, antecedents.
\end{abstract}

\title{
INTRODUCTION
}

Black (1988) defined inter-cultural adjustment as the degree of an individual's psychological comfort with various aspects of a host country and put forward three, unfortunately not discrete, facets of adjustment: work, interaction and general adjustment (Bhaskar-Shrinivas, et al., 2005; Haslberger, Hippler and Brewster, 2014).

In most of the literature, however, it is assumed that intercultural adjustment equates with job performance, even though few if any of the relevant researchers have measured that aspect (Lazarova and Thomas, 2012; Bhaskar-Shrinivas, Harrison, Shaffer and Luk, 2005; Hechanova, Beehr and Christiansen, 2003). This may be partly because neither the notion of adjustment nor the notion of performance are clearly specified, indeed they overlap in some studies, and partly because adjustment measures include a number of different domains (Haslberger et al., 2014): adjustment to the work domain is obviously more likely to be linked directly to work performance. Moreover, the literature on expatriate adjustment also tends to ignore the effects of time, which is obviously at the core of the adjustment process - expatriates will be more adjusted as they spend more time in a country (Bhaskar-Shrinivas et al., 2005; Hippler, Brewster and Haslberger, 2015). Pinder and Das (1979) and Pinder and Schroeder (1987) used the notion of perceived time to proficiency in the context of transfers within one country. The authors (1987) define time to proficiency (TTP) as "the time required for employees to become proficient in their jobs following a transfer" (p. 336). TTP following a transfer includes two different aspects. First, it requires the 
individual to meet the competencies in the official demands of that job (Barnard, 1938), or 'in-role performance', the undertaking of core technical duties of the job (Fisher, 2003). Second, TTP requires the individual to be proficient in the informal, social demands of the job (Barnard, 1938). This aspect of job effectiveness includes the extent to which a person's job behaviour is congruent with a role sender's expectation (Tsui, 1984). Using this notion of TTP, we define expatriates' TTP as the time it takes expatriates, after starting the foreign assignment, to become proficient, i.e. to reach full performance in the official and informal demands of their job (Waxin, Roger and Chandon, 1997; Waxin, et al., 2016). So, whereas the concept of work adjustment measures the degree of adjustment of an individual at a certain point in time, the concept of TTP measures the length of time it takes expatriates to reach an acceptable performance level in their new international assignment. Harrison and Shaffer (2005) found that a long expatriate TTP is a strong negative predictor for overall performance.

TTP is important for the expatriate, because proficiency is positively related to job satisfaction and psychological well-being (Aryee and Stone, 1996). Expatriate TTP is important for the employer because as expatriates become more proficient, they becomes more valuable for the organisation. Until the expatriate becomes proficient, the global expatriation costs are greater than the total contribution that the expatriate makes to the organisation (Pinder and Das, 1979). Multinational enterprises (MNEs) have struggled with the measurement of their return on investment from expatriates (McNulty, De Cieri and Hutchings, 2009; McNulty and Inkson, 2013). A simpler measure may be useful for assessing the value of their expatriation assignments. In addition, any individual antecedent that can shorten their TTP will be valuable and could be an input into the selection process.

There has been little research into assigned expatriates' TTP and its antecedents (Waxin, 2000; 
Waxin et al., 1997, 2016; Selmer, 2006), nor into the relative importance of the different individual and contextual antecedents in predicting expatriates' cross-cultural competence, adjustment and performance (Wang et al., 2017). Most of the research examining individual variables on expatriate effectiveness has focussed on American expatriates assigned to a single host country (Bhaskar-Shrinivas, Harrison, Shaffer, \& Luk, 2005). Thus, our research objectives are twofold: first, to examine the individual variables that facilitate expatriate TTP and, second, to test the moderator effect of the home country on the relationship between these individual variables and expatriate TTP.

We develop the paper as follows. First, we review the literature, examining the individual antecedents of expatriate TTP, and the potential moderating effects of home country, to develop hypotheses, encapsulated in a new model of expatriate TTP. Second, we outline our methodology. We then successively present, and discuss, the study's findings. Finally, we present the limitations, implications and conclusions of our research.

\section{TIME TO PROFICIENCY AND ITS ANTECEDENTS}

\section{The individual antecedents of Time to Proficiency (TTP)}

Individual antecedents are important in explaining expatriates' cross cultural adjustment (Huang, Chi and Lawler, 2005; Lauring, Selmer and Kubovcikova, 2017, Peltokorpi and Froese, 2014). But what are these individual antecedents? Mendenhall and Oddou (1985) initiated this line of research in a conceptual paper. Their analysis is empirically derived, rather than, for example, following the more accepted and tested dimensions of cognition, behaviour and affect (Haslberger et al., 2014), but it has been influential. Mendenhall and Oddou (1985) identified four dimensions 
of competencies facilitating expatriates' adjustment process: 'perceptual' relates to the expatriate's ability to understand why foreigners behave as they do; 'others-oriented' relates to the expatriate's ability to interact effectively with host-nationals; 'self-oriented' relates to the expatriates' selfesteem, confidence and mental hygiene; and 'cultural', not a personal attribute but one we include as a mediator in our analysis below. We use the insights in that model, and in later literature, to develop the individual antecedents we test here.

Cultural openness. Mendenhall and Oddou (1985)'s 'perceptual' dimension refers to the ability to understand the meaning of host nationals' behaviour. It reduces uncertainty in interpersonal relations, facilitating adjustment. Well-adjusted expatriates tend to interpret the behaviour of the host country's inhabitants without judging them (Kraimer, Wayne and Jaworski, 2001). Cerdin (1999) operationalised the perceptual dimension, labelling it 'openness' and found that cultural openness predicted expatriates' interaction and general adjustment. Culturally open expatriates are likely to gain acceptance and social support of their local colleagues, and thus become proficient more quickly.

Social orientation is the ability to create and maintain relationships with individuals from other cultures (Mendenhall and Oddou, 1985). Social orientation has been given different labels, such as people orientation (Shaffer et al., 2006), relational abilities (Jordan and Cartwright, 1998), or relational skills (Bhaskar-Shrinivas et al., 2005). People orientation facilitated work adjustment and contextual performance (Schaffer et al., 2006), and proactivity in social relations facilitates work adjustment (Peltokorpi and Froese, 2012). There are surprisingly few studies of social orientation, but those that exist, even when they include stage of organisational growth (Dunbar, 1992), or organisational dissimilarity (Guillaume, van Knippenberg and Brodbeck, 2014), lead us to expect a positive effect on expatriate TTP. Local subordinates perceived expatriates' relational 
skills as the most important competencies for successful expatriate adjustment (Templer, 2010). It seems likely that an expatriate's social orientation will have an impact on their time to proficiency.

Willingness to communicate. Following Mendenhall and Oddou (1985), we define this ability as the individual's confidence and willingness to use the host culture's language or any other common language to communicate with locals. Communication skills may be the most important competencies for international assignments (Seak and Enderwick, 2008). Black (1990) operationalized the concept of willingness to communicate, and Cerdin (1999) refined it, finding that willingness to communicate, was positively related to expatriate adjustment, and Mol et al., (2005) found it to be positively related to expatriate performance.

Confidence in one's technical ability. There is considerable evidence in the expatriate selection literature that technical competency has traditionally been and continues to be the primary decision criterion used by MNEs across multiple countries (Caligiuri, Tarique and Jacobs, 2009). Confidence in one's technical ability is positively related to expatriates' work adjustment (Ben Ameur, 2010; Cerdin, 1999). It seems reasonable to suggest that someone struggling to make an impact in a new environment is going to find that more difficult if they see themselves as less than capable of dealing even with the technical side of the job.

Active stress resistance. The ability to deal with stress is a key factor for intercultural effectiveness (Lazarus and Folkman, 1984; Wang, et al. 2014). The ability to tolerate stress is positively related to interaction and work adjustment (Schaffer et al., 2006) and expatriates who manage stress effectively demonstrate better adjustment (Wang et al., 2014). However, there has been little research on the topic (Takeuchi, et al., 2005). Folkman, et al., (1986) identify four different strategies that individuals use to fight stress in the workplace: changing one's environment (e.g. changing procedures), actively seeking information or training, psychologically re-evaluating the 
situation and withdrawing psychologically. Feldman and Thomas (1991) suggest that the first two strategies, external and active, are positively correlated with expatriation success, and proactivity has been found to predict expatriate performance (Stroppa and Spieß, 2011). We define active stress resistance as the ability to naturally and preferably resort to active (rather than passive) and external (rather than psychological) stress coping strategies.

Prior international experience. Many current expatriates have been expatriates before (Suutari, Tornikoski and Mäkelä, 2012). Existing research presents inconsistent findings regarding the relationship between prior international experience and expatriates' adjustment and performance. Nicholson (1984) suggested that employees who are frequently mobile learn how to adjust to new work settings, as each successive transfer helps them become comfortable and productive faster and more easily. Quality might be more important than length (Church, 1982). Takeuchi, et al., (2005) differentiated between different aspects of international experiences to include non-work, work, and culture-specific experiences, and found that prior international experience was positively associated with cross-cultural adjustment. Caligiuri et al. (2009) found that prior international experience significantly predicts expatriates' success and recommended including prior international experience in the expatriate selection criterion, whilst Kraimer, Shaffer and Bolino (2009) suggested that the relationship might be curvilinear. In their meta-analysis, BhaskarShrinivas et al. (2005), found that prior international experience was positively, but only weakly, related to work adjustment. Although the exact influence of prior international experience on expatriate success is still unclear, it may lead to the development of some cross-cultural abilities (Şahin, Gurbuz and Köksal, 2014). More extensive past experience might be expected to be associated with shorter expatriate TTP.

On the basis of the discussion so far, we propose: 
Hypotheses 1. High scores on cultural openness (H1a), social orientation (H1b), willingness to communicate (H1c), confidence in one's own technical abilities (H1d), active stress resistance (H1e), and previous international experience (H1f) will be negatively related to expatriate TTP.

\section{Home country effect}

Mendenhall and Oddou (1985) assumed that generic cross-cultural skills help expatriates adjust effectively regardless of context (Wang et al., 2017). The relative importance of the different individual antecedents in predicting expatriates' cross-cultural competence is unclear: inconsistencies in previous findings imply that the general cross-cultural skills model is not always valid across different contexts and cultures (Wang et al., 2017). Conceptual models on the impact of individual antecedents on expatriates' adjustment usually overlook both the expatriates' host (Ward, Leong, and Low, 2004) and home country contexts (Wang et al., 2017). We argue that expatriates' home country will moderate the impact of individual antecedents on TTP. We controlled both the home and the host country to take context into account.

Countries vary in their values and cultures (Hofstede, 2001; House, Hanges, Javidan, Dorfman and Gupta, 2004). Culture can be defined as "shared motives, values, beliefs, identities, and interpretations or meanings of significant events that result from common experiences of members of collectives that are transmitted across generations" (House et al., 2004: 15). Researchers using the cultural approach usually use countries' average scores on cultural dimensions to explain differences in outcomes that seem to originate from the differences in cultural values and practices. Since nearly all studies of culture conflate culture with 'country', assuming a similarity of culture within the country and distinctiveness between countries, we use those studies to, partially, explain expatriate TTP. We use these cultural measures as indicators of national difference, arguing that 
the cultural differences indicated in these 'country of origin' effects will moderate the hypotheses we have offered so far. We note the important critiques of the cultural literature (see e.g. Gerhart, 2008; McSweeney, 2002) and that the scores offered by Hofstede and GLOBE are incompatible even when they have the same titles (Avloniti and Fragkiskos, 2014). Our research being exploratory, our hypothesis is a form of what is in effect a proposition to be tested; we suggest differences but do not advance specific country relationships until we have assessed the empirical results:

H2. Home country will moderate the relationships between the individual antecedents and expatriate TTP.

$<<$ Figure 1. Our research model and hypotheses about here $>>$

\section{METHODOLOGY}

\section{Sample description}

The sample included 224 respondents, (191 males and 33 females) from four different home countries: France (56), Germany (53), Korea (60), and Scandinavia ${ }^{1}$ (57), who were assigned expatriates in New Delhi, India. They were working in multinational companies headquartered in their home countries, in general management or high technical positions, for a maximum period of four years in India. Like all the research cited so far, our focus is on assigned expatriates sent by their home headquarters to the foreign country. The respondents, on average, were 38 years old $(s d=7.5)$, reported 2.16 years $(s d=2.35)$ of prior international experience, and had job tenure 
in their current position of 20.49 months $(s d=8.89)$ at the time the data was collected. In broad terms, our data reflects the demographic make-up of assigned expatriates found in other studies (Shaffer et al., 2006).

\section{Measures}

The final key measures are listed in Appendix 1.

Individual variables. To measures cultural openness ( 3 items), social orientation ( 3 items), willingness to communicate ( 4 items) and confidence in technical ability (3 items), we simplified Cerdin's (1999) scales. First, we analysed the confirmatory analysis of Cerdin's scales (Cerdin, Chandon, Waxin, 1999). Second, we conducted a pre-test with a convenience sample of 20 expatriates of the different cultural groups of interest (Waxin, 2005, Waxin, 2000) to eliminate superfluous, unclear and redundant items. The four final measures are shorter and show increased Cronbach's alphas. Respondents were asked to report their level of agreement on a seven-point Likert scale, ranging from 1: Strongly disagree, to 7: Strongly agree.

To measure active stress resistance, we created an index by asking respondents to distribute 100 points among four types of anti-stress strategies (Folkman et al., 1986). Then we added together the points given to the two active stress resistance strategies (ASR1, ASR2), giving us a score out of 100 for each respondent.

To measure previous international experience, we created an index by asking the number of months spent abroad (working, studying, living abroad) before the actual expatriation experience in India. Respondent answers ranged from a minimum of 0 month to a maximum of 132 months (11 years), with a mean of 26 months (2.16 years), and a median of 18 months.

Expatriate time to proficiency (TTP). To measure TTP, we adapted the four items used by Pinder 
and Schroeder (1987) to the expatriates' context (Waxin et al., 2016). We asked them to estimate how much time it had taken to become proficient at their new jobs, formally (two items, TTP1 and TTP2) and informally (TTP3, TTP4). For the four items of the scale, we used answers expressed in number of months and weeks, allowing more precision in the results. We then computed the average in weeks of these four items. Like Pinder and Schroeder (1987), we verified that this measure was not significantly correlated with seniority in the expatriate's position (respectively $\mathrm{r}=.12, \mathrm{~ns})$.

Home country. The home countries of our respondents (France, Germany, Korea, and Scandinavia) are culturally very different from each other: their scores on the cultural dimensions used by both the GLOBE (eds. House et al. 2004) and Hofstede (1991) studies are distinctive, and they belong to different 'culture clusters' in both studies.

\section{Analytical Techniques}

We use partial least squares (PLS) graphs (Chin, 1998). PLS has become an increasingly popular multivariate analysis technique used by human resource management researchers (Ringle, et al., 2018). Three reasons justify our use of PLS. First, hypothesised relationships linking individual antecedents to TTP have largely remained unexplored. PLS is more applicable in research areas where theoretical knowledge is not as strong as that demanded by covariance-based approaches inherent in LISREL, AMOS and EQS, and can be used to suggest where relationships might or might not exist (Hair, Ringle and Sarstedt, 2011). Second, PLS can be used with small sample sizes (as in our four home country groups) because the iterative algorithm behind PLS estimates parameters in only small subsets of a model during any given iteration (Whittaker, Ledden, and Kalafatis, 2007). Third, PLS can be used for both exploratory and confirmatory applications, since, unlike covariance-based approaches, it does not try to go beyond the data (Wold, 1982). 
Consequently, PLS made it easier to explore the differences between expatriates from four different home countries by comparing their path coefficients (Chin, 2009).

To test the first hypothesis, a main effects model was run and evaluated on the basis of the $R^{2}$ values for expatriate TTP, the size, $t$-statistics and significance level of the structural path coefficients (based on 5000 bootstrapping runs), and the Stone-Geisser $Q$-square test (Geisser 1975; Stone 1974) for predictive relevance (Hair, Sarstedt, Hopkins and Kuppelwieser, 2014).

To test the second hypothesis, the moderating role of home country was assessed through group comparisons. The differences between the four home country groups were analysed using path coefficients' comparison using a parametric procedure from (Chin, 2009), as originally described by (Keil et al., 2000). This procedure is shown below and shows a t-distribution with $\mathrm{m}+\mathrm{n}-2$ degrees of freedom:

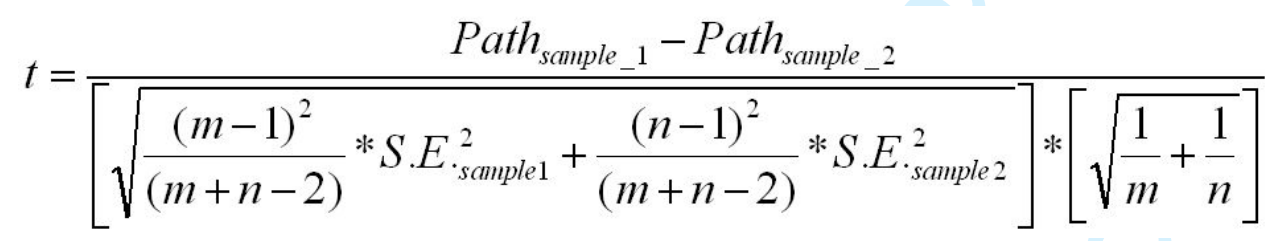

where path $=$ path coefficient; $S E=$ standard error; $m=$ sample 1 size and $n=$ sample 2 size. It determines a t-value with $m+n-2$ degrees of freedom dependent on the standard error of the estimated path coefficients from bootstrapping as well as the sample size (Chin, 2009).

\section{FINDINGS}


We first present the descriptive statistics, to indicate the general responses to the constructs measured. The correlations, means, standard deviations and Cronbach's alpha of the variables are presented in Table 1. Significant differences were detected for previous international experience. Specifically, the mean score for previous international experience was higher for Scandinavian respondents than for expatriates from France, Germany and Korea. No significant differences were detected for active stress resistance.

\section{$<<$ Insert Table 1: Correlations, means and standard deviations of construct measures} about here $>>$

\section{Measurement Model Assessment}

The measurement model was assessed by examining individual item reliability, internal consistency and discriminant validity which are acceptable if there exist other indicators in the block for comparison. All of the loadings (item reliability) exceed Chin (1998)'s suggested threshold of .50 or .60 , and the more stringent threshold of .707 suggested by Barclay, Higgins and Thompson 1995. Table 2 summarises the measurement model results for the overall sample. We then assessed whether the same measurement model held for each home country group by analysing the measurement model invariance between respondents from the four home country groups, using the bootstrapping technique and the Fishers $z$ transformation. Table 2 shows that most individual item loadings do not differ significantly across the four home country groups.

Table 2 also shows composite reliability (internal consistency) and average variance extracted (AVE) scores for the overall sample and the four sub-samples. All composite reliabilities are above 
the .70 acceptable threshold (Gefen, Straub and Boudreau, 2000) and range from .93 to .98. AVE scores range from .80 to .95 across the four groups. When AVE is greater than .50 , the variance shared with a construct and its measures is greater than error (Fornell and Larcker, 1981). All constructs in the model also meet the Fornell and Larcker (1981) criterion of discriminant validity. Recently, Henseler, Ringle and Sarstedt (2015) have suggested that those criterion and crossloadings are insufficiently sensitive to detect discriminant validity problems. To address this issue, we used their new heterotrait-monotrait ratio of correlations. Specifically, we computed the heterotrait-monotrait ratio criteria for each pair of constructs on the basis of the item correlations. The computation yielded values between .07 and .16 in the overall sample. Using a conservative criterion of .85 (Kline, 2011), our findings corroborate the existence of discriminant validity for the overall sample. Similar values exist for each pair of constructs in each expatriate home country group, thus demonstrating discriminant validity for the four subsamples.

\section{$<<$ Insert Table 2: Model validation results about here $>>$}

\section{Structural Model Results}

The structural model results for the main effects model are shown in Table 3. Falk and Miller (1992) suggest that the variance explained $\left(R^{2}\right)$ for endogenous variables should be greater than .10.

To test our first hypothesis, we examine the results in the global sample. Collectively, the individual antecedents explain $20 \%$ of the variance in assigned expatriates' TTP. Results in Table 3 show that four of the six individual antecedents of expatriate TTP are significant. Confidence in 
technical ability $(\beta=-.14, t=-2.06)$, social orientation $(\beta=-.13, t=-1.98)$, willingness to communicate $(\beta=-.21, t=-3.05)$ and active stress resistance $(\beta=-.17, t=-2.65)$ all demonstrate a significant negative relationship with TTP. H1b, 1c, 1d and 1e are therefore supported. However, cultural openness and previous international experience both demonstrate a non-significant relationship with TTP $(\beta=-.05, t=-.86) ; \beta=-.08, t=-1.42)$, so H1a and H1f are rejected.

The Stone-Geisser test of predictive relevance was also performed to further assess model fit in PLS analysis (Geisser, 1975; Stone, 1974). Using omission distances of 10 and 25 produces similar results, indicating that the estimates are stable. Values greater than zero indicate that the model has predictive relevance. The communality $Q$-square $\left(Q^{2}\right)$ for expatriate TTP was greater than 0 .

To test our second hypothesis, the moderating role of home country was assessed through group comparisons. The structural model results for the four subsamples are shown in Table 3. The relationship between cultural openness and TTP is negative and significant in only one country sample, the French one $(\beta=-.28, t=-2.11)$. Social orientation $(\beta=-.31, t=2.56)$ and confidence in technical ability $(\beta=-.46, t=-4.46)$ demonstrate significant negative relationships with TTP in the Scandinavian sample only. The relationship between willingness to communicate and TTP is negative and significant for Korea $(\beta=-.58, t=-4.65)$ and Germany $(\beta=-.25, t=1.80)$ only. Active stress resistance demonstrates a negative and significant relationship with TTP for expatriates from France $(\beta=-.35, t=-3.24)$, Germany $(\beta=-.27, t=-1.98)$ and Scandinavia $(\beta=$ $-.25, t=-2.50)$, but the relationship between active stress resistance and TTP is not significant for Korea. Previous international experience demonstrates a negative and significant relationship with TTP for expatriates from France $(\beta=-.18, t=-1.84)$ and Korea $(\beta=-.17, t=-1.81)$. Collectively, the individual antecedents explain the least variance in TTP in the German sample (21\%) and the highest variance in TTP in the Scandinavian sample (47\%). These findings are complex but clearly 
suggest that the individual antecedents of TTP vary across home country. Therefore, H2 is supported.

\section{$<<$ Table 3. PLS main effects model results for overall sample and home country groups about here $>>$}

\section{DISCUSSION}

Our results show that individual antecedents interact with host country to predict expatriate TTP. This is a key contribution, as too few studies examine the links between individual antecedents, home country and expatriates' work outcomes simultaneously (Bhaskar-Shrinivas et al., 2005; Peltokorpi and Froese, 2014)

First, the direct effects of individual antecedents on TTP contribute to the scarce literature on the link between individual antecedents and expatriates' work-related outcomes (Peltokorpi and Froese, 2014; Shaffer et al., 2006). We found that on our global sample, four variables - confidence in technical ability, social orientation, willingness to communicate and active stress resistance are negatively related to TTP. This is probably because these four variables are directly relevant to the work situation where TTP is measured.

Cultural openness did not show any significant relationship with TTP in our global sample. In previous literature cultural openness has not been connected with work adjustment, which is what we are concerned with here. The results for the French sample may reflect France's long international (colonial) history.

Previous international experience did not show any significant relationship with TTP in the global 
sample either. TTP, as defined by Pinder and Schroeder (1987), is designed as a transfer-specific concept, dependent on individual and assignment-specific variables. This may be the reason why previous international experience does not have a significant effect on expatriate TTP. In the previous literature, previous international experience had been found to be positively related to expatriate adjustment (Selmer, 2007; 2009), but not significantly related to job performance (Mol et al., 2005). It is interesting to note, however, that Waxin et al. (1997) found that previous international experience was only negatively related to French expats' TTP in Norway when the new assignment was perceived as 'similar but more difficult'.

Second, the results in the country-specific samples are more complex. We found that the individual antecedents of TTP vary according to expatriates' home country. So, not only the individual antecedents per se, but also their interaction with expatriates' home country, partially predict TTP. Indeed, the percentages of TTP variance explained in the home country samples were higher than in the global sample.

Active stress resistance was significantly and negatively related to TTP in the global sample, and in all the country samples, except the Korean one. These results confirm previous work (Feldman and Thomas, 1991; Lauring et al., 2017; Wang et al., 2014) that active and external coping strategies are positively correlated with expatriate success. Expatriates who score high on stress tolerance should be more able to display flexible verbal and nonverbal behaviours that put others at ease in cross-cultural situations (Rose, Ramalu, Uli and Kumar, 2008). Since Korea and India are both high context, tight, vertical collectivist cultures (Gelfand et al., 2011), individual stress resistance strategies may be less relevant for Koreans.

Only in the French sample was cultural openness negatively related to expatriate TTP. We expected cultural openness to have a more important negative effect on TTP, because India is a 
'tight' cultural country (Gelfand et al., 2011), making it harder to understand and adapt to the work environment. In their meta-analytic analysis, Shaffer et al. (2006) found that cultural flexibility was not significantly related to adjustment or to task performance. The fact that cultural openness explains TTP for French expatriates in India is a unique feature that requires further research.

Confidence in technical ability was found to be significant in the global sample, but only in the Scandinavian sub-sample. Perhaps because of their low power distance Scandinavian expatriates rely more on their confidence in their own higher technological capability to acquire legitimate authority (Hofstede, 1984).

Willingness to communicate was significant in the global sample, and in the German and Korean sub-samples. Willingness to actively communicate with local subordinates, colleagues and bosses has been found to be positively related to expatriate adjustment (Cerdin, 1999). It makes intuitive sense that willingness to communicate has more of an effect in the more collectivist and more uncertainty-avoidant countries. It may also be the case that the accents of German and Korean expatriates may be more difficult for Indians to understand and so they may need to make more of an effort to verify that they have been understood.

Social orientation was significantly related to TTP in the global sample, but only in the Scandinavian sub-sample. The results in the other home country samples contradict previous research that suggested that people orientation facilitated work adjustment and contextual performance (Schaffer et al., 2006; Peltokorpi and Froese, 2012). This might be an indication of the limitations of the adjustment measures used in the previous research or it might be the host country context having an impact here. Social orientation could be a less significant antecedent of TTP in a tight, vertical, collectivist country (like India) where talkative, outgoing behaviour disturbs traditional relationships and in-group boundaries (Peltokorpi and Froese, 2012). 
Previous international experience reduced TTP among Koreans and French expatriates. We note that these expatriates reported less previous international experience than Scandinavians. This may be an indication that most cross-cultural learning takes place in the first and second assignments and then the learning curve flattens out.

Overall, our country sub-sample results show that the impact of certain individual antecedents on TTP are not universal but dependent on the home country. However, the partial, amorphous and contested measurements of the concept of culture make it difficult to draw any direct correlations. Home country has a clear effect on the relevance of individual variables' impact on TTP but more research is needed to establish exactly how. Moreover, the impact of individual antecedents on TTP might also depend on the characteristics of the expatriates' host culture, India. Our research refines the results of many previous studies that have implicitly assumed uniformity in the predictive power of personality traits, regardless of home and host country context (Wang et al., 2017).

\section{$<<$ Insert Table 4. Summary: individual antecedents of expatriate TTP on the global and four different Home Country samples about here $>>$}

\section{CONCLUSIONS}

\section{Limitations and suggestions for future research}

The first limitation of our research relates to the sample. Only four countries of origin and one host country are examined. Due to sample size limitations, Danish, Norwegian and Swedish expatriates had to be bundled together within one sample called 'Scandinavia'. Moreover, research suggests that cultural values can vary considerably inside the same country, especially in multi-ethnic 
countries, like India (Lenartowicz and Roth, 2001). That is why we studied expatriates in just one major city, New Delhi. Future studies should include more countries of origin, more host countries and more respondents.

Other limitations relate to our measures and data collection. The questionnaire was written in English, which, although it is the working language of expatriates in India, is a foreign language for all the respondents. The dependent and independent variables were collected simultaneously via a single, self-report questionnaire from individual respondents, at a single point in time, which may artificially increase the strengths of some relationships. However, Nicholson (1984) noted in his person-centred theory of work role transitions that what is operationally important is a person's subjective perceptions of the reality, following the reasoning that what is perceived as real is real in its consequences. Mol et al. (2005) found that personality scales in expatriate studies did not have any self- and other-rated moderation effect. Still, in order to generate more reliable answers from the participants, we mixed the items of the different scales and presented them in random order. Waxin et al. (1997) found, in their Norwegian sample, that the difference between the selfreported and the supervisors' measure of the expatriate's TTP were not significantly different.

Finally, expatriate TTP may be influenced by other individual and contextual variables, and additional empirical studies would be useful. For example, the expatriate's perceptions of job dissimilarity or complexity could moderate the relationships between TTP and its antecedents.

Regarding other avenues of research, it would be interesting to examine the individual and organisational antecedents of self-initiated expatriates' TTP, in different contexts.

\section{Theoretical contributions}

Despite these limitations our results are robust. The first contribution of this article is that, using 
TTP, we offer a new way of thinking about expatriate adjustment to the work domain, that is more straightforward and more directly linked to work performance. Expatriate adjustment and expatriate performance have been covered in two extensive literatures, but the results are not only equivocal but have very limited connection to each other. Assessment of time to proficiency is not only relatively straightforward but it is, for expatriates and for the host and home country of the MNE that is employing them, perhaps the crucial issue for their assignment. The quicker expatriates become proficient in their work, the more comfortable they will feel in that domain of their new environment and the faster the MNE will see a positive relationship between their investment in the expatriate and the outcomes of the work they are doing.

The second contribution of this paper is to enrich and support the recent literature that highlights the importance of context in the research on expatriates' cross-cultural effectiveness and management. Froese and Peltokorpi (2011) and Peltokorpi and Froese (2014) demonstrated that host country context affects expatriate job satisfaction and adjustment. Waxin et al. (2016) found that the mean scores of assigned expatriates' TTP in a specific host country significantly vary across home countries, and that the organisational antecedents of expatriates' TTP and their relative importance also vary significantly across expatriates' home countries. This present study provides evidence that home country also has an impact on the individual antecedents of expatriates' TTP.

The third contribution of this article is that we refined and validated the measures for cultural openness, social orientation, willingness to communicate, and confidence in one's technical ability. The new measures are shorter, with only three or four items, and show an increased Cronbach's alpha. We also proposed a simple, new measure of active stress resistance. 


\section{Practical implications}

This study has practical implications for HRM professionals and expatriates, relating mainly to selection, cross-cultural training and assessment.

First, our results show that individual characteristics should be taken into account in expatriate selection. Selection for international assignments is generally based mostly on technical expertise and previous performance and the logic of doing so is confirmed by our evidence. Individual variables are much less commonly considered, but our results confirm that they should be. Moreover, recruiters should consider different individual variables depending on the home and host country cultures.

Second, expatriates can also benefit from our research to get a better understanding of the individual variables that impact their TTP and to prepare themselves better for their new assignment. Our results suggest that expatriate TTP can be reduced by pre-departure and onsite training of expatriates (Feitosa et al. 2014). Host country nationals should be trained too, as a better understanding of cultural differences in work-interactions and leadership styles can reduce cultural misunderstandings and negative stereotyping (Peltokorpi and Froese, 2014). Leiba-O' Sullivan (1999) distinguished between stable competencies - such as ability and personality - that are relatively fixed and may constrain the potential to develop a skill, and dynamic competences, such as knowledge and skills, that can be enhanced through training. Several authors argued that cultural flexibility (Van der Zee \& Van Oudenhoven, 2000), social initiative (Van der Zee \& Van Oudenhoven, 2000), and stress tolerance (Hammer et al., 1978) could be enhanced by training. Based on our global sample, enhancing the individual dynamic competencies of expatriates could be a good organisational investment to increase their effectiveness. 
Third, TTP offers a simple and easily measured concept relating directly to an expatriate's work performance. Though it has obvious limitations and does not answer the key financial issue for MNEs, the concept of TTP provides easily understood evidence of the contribution of assigned expatriates, which has been, as McNulty and Inkson (2013) pointed out, a previously overlooked factor in attempts to establish overall return on investment, and hence it may be more useful to MNEs than complex and expensive attempts to measure return on investment. We contribute to expatriate management research by examining the individual variables that impact TTP, examining the moderating effects of home country on these individual variables, and conducting research in India, a big emerging country.

Finally, our results demonstrate that, when discussing expatriate selection and management, context should be examined and assessed carefully. 


\section{REFERENCES}

Aryee, S. and Stone, R. J., (1996), "Work experiences, work adjustment and psychological wellbeing of expatriate employees in Hong Kong”, International Journal of Human Resource Management, Vol.7 No. 1, pp. 150-164.

Avloniti, A. and Fragkiskos, F., (2014), "Unbundling the differences between psychic and cultural distance: an empirical examination of the existing measures”, International Business Review, Vol. 23 No. 3, pp. 660-674.

Barclay, D.K., Higgins, C., and Thompson, R., (1995), "The partial least squares approach to causal modeling: personal computer adoption and use as an illustration", Technology Studies, Vol 2, pp. 285-324.

Barnard, C., (1938), The Functions of the Executive, Cambridge, Mass.: Harvard University Press.

Ben Ameur, A., (2010), "L'adaptation au travail des cadres expatriés: comment concilier performances économique et sociale dans un contexte de diversité culturelle?", Humanisme et Entreprise, Vol. 300, pp. 57-76.

Bhaskar-Shrinivas, P., Harrison, D.A., Shaffer, M. A.and Luk, D.M., (2005), "Input-based and time-based models of international adjustment: meta-analytic evidence and theoretical extensions", Academy of Management Journal, Vol. 48 No. 2, pp. 257-281.

Black, J. S., (1990), "The relationship of personal characteristics with the adjustment of Japanese expatriate managers", Management International Review, Vol. 30, pp. 119-134.

Caligiuri, P., Tarique, I. and Jacobs, R., (2009), "Selection for international assignments", Human Resource Management Review, Vol. 19 No. 3, pp. 252-262. 
Cerdin. J-L., (1999), “L'adaptabilité des cadres français expatriés”, Gestion, Septembre-Octobre, pp. 56-70.

Cerdin J-L., Chandon J-L., Waxin M-F., (1999), "The Adaptability of the French expatriates, a confirmatory analysis”, EIASM Workshop on International Human Resource Management, Carlos III University, Madrid.

Chin, W., (1998), “The partial lease squares for structural equations modelling”, in Marcoulides, G.A. (Ed), Modern methods for business research: New-York, Lawrence Erlbaum Associates, pp. 295-336.

Chin, W., (2009), Frequently asked questions - partial least squares and PLS-graph, http://discnt.cba.uh.edu/chin/plsfaq.htm.

Church, A. (1982), “Sojourner Adjustment”, Psychological Bulletin, Vol. 91 No.3, pp. 540-572.

Dunbar, E. (1992), “Adjustment and satisfaction of expatriate US personnel”, International Journal of Intercultural Relations, Vol. 16 No. 1, pp. 1-16.

Falk, R.F. and Miller, N.B. (1992), A primer for soft modelling, University of Akron Press, Akron

Feitosa, J., Kreutzer C., Kramperth A., Kramer W. S. and Salas, E., (2014), "Expatriate adjustment: considerations for selection and training”, Journal of Global Mobility, Vol. 2 No. 2 134159

Feldman, D. C. and Thomas. D. C., (1991), "From desert shield to desert storm: life as an expatriate during the Persian Gulf War", Organisational Dynamics, Vol. 20 No. 2, pp. 37-47.

Fisher, C. D. (2003), "Why do lay people believe that satisfaction and performance are correlated? Possible sources of a commonsense theory F", Journal of Organisational Behavior: The 
International Journal of Industrial, Occupational and Organisational Psychology and Behavior, Vol. 24, No 6, pp. 753-777.

Folkman, S., Lazarus, R.S., Dunkel-Schetter, C., DeLongis, A. and Gruen, R., (1986), “Dynamics of a stressful encounter: Cognitive appraisal, coping, and encounter outcomes", Journal of Personality and Social Psychology, Vol. 50 No. 5, pp. 992-1003.

Fornell, C. and Larcker, D.F., (1981), "Evaluating structural models with unobserved variables and measurement error", Journal of Marketing Research, pp. 39-50.

Froese, F. and Peltokorpi V., (2011), "Cultural distance and expatriates job satisfaction", International Journal of Intercultural relations, Vol. 35, pp. 49-60.

Gefen, D., Straub, D.W. and Boudreau, M-C., (2000), "Structural equation modelling and regression: guidelines for research practice", Communications of the Association for Information Systems, Vol. 4 No. 7.

Geisser, S., (1975), "The predictive sample re-use method with applications", Journal of the American Statistical Association, Vol. 70 No 350, pp. 320-328.

Gelfand, M.J., Raver J.L., Nishii, L.H., Leslie, L.M., Lun, J., Lim, B.C. et al., (2011), "Differences between tight and loose culture: a 33 nations study", Science, Vol. 332 No. 60333, pp. 1100-1104.

Gerhart, B., (2008", "Cross-cultural management research: assumptions, evidence, and suggested directions", International Journal of Cross Cultural Management, Vol. 8 No. 3, pp. 259274.

Guillaume, Y.R.F., Van Knippenberg D. and Brodbeck F.C., (2014), "Nothing succeeds like moderation: a social self-regulation perspective on cultural dissimilarity and 
performance", Academy of Management Journal, Vol. 57, pp. 1284-1308

Hair, J., Sarstedt, M., Hopkins, L. and Kuppelwieser, V.G., (2014), "Partial least squares structural equation modeling (PLS-SEM) an emerging tool in business research", European Business Review, Vol. 26 No. 2, pp. 106-121.

Hair, J.F., Ringle C.M. and Marko Sarstedt M., (2011), "PLS-SEM: Indeed a silver bullet”, Vol. 19, pp. 139-152

Haslberger, A., Brewster, C. and Hippler, T., (2014), Managing Performance abroad: A new model for understanding expatriate adjustment, London, Routledge.

Henseler, J., Ringle, C.M. and Sarstedt, M., (2015), "A new criterion for assessing discriminant validity in variance-based structural equation modelling", Journal of the Academy of Marketing Science, Vol. 43 No. 1, pp. 115-135.

Hippler, T., Brewster, C. and Haslberger, A., (2015), "The elephant in the room: The role of time in expatriate adjustment”, International Journal of Human Resource Management, Vol. 26 No. 15, pp. 1920-1935.

Hofstede, G., (2001), Culture's consequences: Comparing values, behaviors, institutions, and organisations across nations (2ed), Thousand Oaks, CA: Sage.

House, R. J., Hanges, P. J., Javidan, M., Dorfman, P. W. and Gupta, V. (Eds.) (2004), Culture, leadership, and organisations: The GLOBE study of 62 societies, Sage, Thousand Oaks.

Huang, T.-J., Chi S-C. and Lawler J.J., (2005), “The relationship between expatriates' personality traits and their adjustment to international assignments", International Journal of Human Resource Management, Vol. 16 No. 9, pp. 1656-1670. 
Jordan, J. and Cartwright, S., (1998), "Selecting expatriate managers: Key traits and competencies", Leadership and Organisation Development Journal, Vol. 19 No. 2, pp. 89-96.

Keil, M., Bernard C. Y. Tan, Wei, K., Saarinen, T., Tuunainen, V. and Wassenaar, A., (2000), “A cross-cultural study on escalation of commitment behavior in software projects", MIS Quarterly, pp. 299-325.

Kline, R. B., (2011), “Convergence of structural equation modeling and multilevel modelling”, in Williams, M. and Vogt, W.P. (Eds.), Handbook of Methodological Innovation, Sage, , Thousand Oaks, CA, pp. 562-589.

Kraimer, M. L., Shaffer, M. A. and Bolino, M. C., (2009), "The influence of expatriate and repatriate experiences on career advancement and repatriate retention", Human Resource Management, Vol. 48 No. 1, pp. 27-47.

Kraimer, M. L., Wayne, S. J. and Jaworski, R. A. A., (2001), "Sources of support and expatriate performance: The mediating role of expatriate adjustment", Personnel Psychology, Vol. 54 No. 1, pp. 71-99.

Lauring, J., Selmer J. and Kubovcikova, A., (2017), "Personality in context: effective traits for expatriate managers at different levels", International Journal of Human Resource Management, pp. 1-26.

Lazarova, M. B. and Thomas, D. C., (2012), "Expatriate adjustment and performance revisited", in Stahl, G.K., Björkman, I. and Morris, S. (Eds.), Handbook of International Human Resource Management, Edward Elgar, Cheltenham, pp. 271-292.

Lazarus, R. S. and Folkman, S., (1984), Stress, appraisal, and coping. New York: Springer. 
Leiba-O'Sullivan, S (1999). The distinction between stable and dynamic cross-cultural competencies: implications for expatriate trainability. Journal of International Business Studies, Vol.30, No. 4, 709-725

Lenartowicz, T. and Roth, K., (2001), "Does subgroup within a country matter? A cross cultural study of motivational domains and business performance in Brazil", Journal of international business studies, Vol. 32 No. 2, pp. 305-325.

McNulty, Y., \& Inkson, K. (2013). Managing Expatriates: A Return on Investment Approach. New York, NY: Business Expert Press.

McNulty, Y., De Cieri, H., \& Hutchings, K. (2009). Do global firms measure expatriate return on investment? An empirical examination of measures, barriers and variables influencing global staffing practices. The International Journal of Human Resource Management, Vol. 20, No. 6, 1309-1326.

McSweeney, B., (2002), "Hofstede's model of national cultural differences and their consequences: A triumph of faith - a failure of analysis", Human Relations, Vol. 55 No. 1, pp. 89-118.

Mendenhall, M. and Oddou, G., (1985), "The dimensions of expatriate acculturation: A review", Academy of Management Review, Vol. 10 No. 1, pp. 39-47.

Mendenhall, M. and Oddou. G., (1991), “Toward a comprehensive model of international adjustment: an integration of multiple theoretical perspectives", Academy of Management Review, Vol. 16 No. 2, pp. 291-317.

Mol, S. T., Born, M. P., Willemsen, M. E. and Van der Molen, H. T. (2005), "Predicting Expatriate Job Performance for Selection Purposes: A Quantitative Review”, Journal of 
Cross-Cultural Psychology, Vol. 36 No. 5, pp. 590-620.

Nicholson, N., (1984), "A theory of work role transitions", Administrative Science Quarterly, Vol. 29, pp. 172- 191.

Peltokorpi, V. and Froese F., (2012), “The impact of expatriate personality traits on cross cultural adjustment: a study with expatriates in Japan”, International Business review, Vol. 21 No. 4, pp. 734-746.

Peltokorpi, V. and Froese F., (2014), "Expatriate personality and cultural fit: the moderating role of host country context on job satisfaction”, International Business review, Vol. 23, pp. 293-302

Pinder, C. C. and Das, H., (1979), "Hidden costs and benefits of employee transfers", Human Resources Planning, Vol. 2 No. 3, pp. 135-145.

Pinder, C. C. and Schoeder, K. G., (1987), "Time to proficiency following job transfers”, Academy of Management Journal, Vol. 30 No. 2, pp. 336-353.

Ringle, C. M, Sarstedt, M., Mitchell, R. and Gudergan S. P., (2018), "Partial least squares structural equation modeling in HRM research", The International Journal of Human Resource Management, DOI: 10.1080/09585192.2017.1416655.

Rose, R.C., Ramalu, S.S., Uli, J., and Kumar, N., (2010), "Expatriate performance in international assignments: The role of cultural intelligence as dynamic intercultural competency", International Journal of Business and Management, Vol. 5 No. 8, pp. 76.

Şahin, F., Gurbuz, S. and Köksal, O., (2014), "Cultural intelligence (CQ) in action: The effects of personality and international assignment on the development of CQ", International Journal of Intercultural Relations, Vol. 39, pp. 152-163. 
Seak, N. and Enderwick, P., (2008), "The management of New Zealand expatriates in China", International Journal of Human Resource Management, Vol. 19 No. 7, pp. 1298-1313.

Selmer, J., (2006), “Adjustment of business expatriates in Greater China: A strategic perspective”, International Journal of Human Resource Management, Vol. 17 No. 12, pp. 1994-2008.

Shaffer, M. A., Harrison, D. A., Gregersen, H., Black, J. S. and Ferzandi, L. A., (2006), "You can take it with you: Individual differences and expatriate effectiveness", Journal of Applied Psychology, Vol. 91 No. 1, pp. 109-125.

Stone, M., (1974), "Cross-validatory choice and assessment of statistical predictions", Journal of the Royal Statistical Society, Series B (Methodological), Vol. 36, pp. 111-147.

Stroppa, C. and Spiess, E., (2011), "International assignments: The role of social support and personal initiative", International Journal of Intercultural Relations, Vol. 35 No. 2, pp. 234-245.

Suutari, V., Tornikoski, C. and Mäkelä, K., (2012), "Career decision making of global careerists”, International Journal of Human Resource Management, Vol. 23 No.16, pp. 3455-3478.

Takeuchi, R., Tesluk, P. E., Yun, S. and Lepak, D. P., (2005), “An integrative view of international experience", Academy of Management Journal, Vol. 48 No. 1, pp. 85-100.

Templer, K. J., (2010), "Personal attributes of expatriate managers, subordinate ethnocentrism, and expatriate success: A host-country perspective", International Journal of Human Resource Management, Vol. 21 No. 10, pp. 1754-1768.

Tsui, A. S., (1984), “A role set analysis of managerial reputation”, Organizational behavior and Human Performance, Vol. 34 No. 1, pp. 64-96. 
Van Der Zee, K. I., and Van Oudenhoven, J. P. (2000), "The multicultural personality questionnaire: a multidimensional instrument of multicultural effectiveness", European Journal of Personality, Vol. 14 No. 4, pp. 291-309.

Wang, D., Fan, D., Freeman, S. and Zhu, C. J., (2017), "Exploring cross-cultural skills for expatriate managers from Chinese multinationals: Congruence and contextualization”, Asia Pacific Journal of Management, Vol. 34 No. 1, pp. 123-146.

Wang, D., Feng, T., Freeman, S., Fan, D. and Zhu, C.J., (2014), "Unpacking the "skill-crosscultural competence" mechanisms: Empirical evidence from Chinese expatriate managers", International Business Review, Vol. 23 No. 3, pp. 530-541.

Ward, C., Leong, C.H. and Low, M., (2004), "Personality and sojourner adjustment: an exploration of the Big Five and the cultural fit proposition", Journal of Cross-Cultural Psychology, Vol. 35 No. 2, pp. 137-151.

Waxin, M-F. (2000). L'adaptation des cadres expatriés en Inde: Ses déterminants et l'effet de la culture d'origine, Unpublished Ph.D. Dissertation, IAE Aix-en-Provence, France.

Waxin, M-F., (2005), "The adjustability of the expatriate manager: Proposal of an improved measurement scale", 20th Workshop on Strategic Human Resource Management, EIASM, Brussels, April 28-29. Available at: https://dspace.aus.edu/xmlui/bitstream/handle/11073/16415/2005_Waxin_Adjustability _improved_measurement_scale_EIASM_SHRM_posted.pdf?sequence=1\&isAllowed $=$ $\mathrm{y}$

Waxin, M-F., Brewster, C., Ashill, N., Chandon, J-L., (2016), “The impact of expatriates' home country culture on their time to proficiency: empirical evidence from the Indian context”, Journal of Developing Areas, Vol. 50, No. 4, pp. 401-422.

Waxin, M-F., Roger, A., and Chandon, J-L., (1997), “L'intégration des expatriés dans leur 
nouveau poste, une analyse contingente et quantitative", in Tremblay M. and Sire B. (Ed.), G.R.H. face à la crise, G.R.H. en crise, Presses HEC, Montréal.

Whittaker, G., Ledden, L. and Kalafatis, S. P., (2007), "A re-examination of the relationship between value, satisfaction and intention in business services", Journal of Services Marketing, Vol. 21 No 5, pp. 345-357.

Wold, H., (1982), "Systems under indirect observation using PLS", in Fornell C. (Ed.), A Second Generation of Multivariate Analysis, Praeger, New York.

Our 'Scandinavian' category includes 35 Danish, 13 Swedish and 9 Norwegian expatriates. We used the terms 'country' or 'national sample' rather than culture, in order to reflect our data more accurately, as we identified country of origin but did not test for culture. 


\section{Appendix 1. The key measures}

Time To Proficiency (.... months and .... weeks, then recoded into weeks) (TTP) $(\alpha=.95)$

TTP1. How many months did it take you to become effective at your new job following your last expatriation?

TTP2. How quickly do you feel you became proficient at your new job following your expatriation?

TTP3. How many months did it take you to get to know your way around the informal networks at your new job?

TTP4. Overall, how quickly did you start to feel comfortable in your new work setting following your last transfer?

\section{Individual variables.}

Indicate your level of agreement with the following statements $(1=$ Strongly disagree, $7=$ Strongly agree)

Cultural openness $(\mathrm{CO})(\alpha=.93)$

CO1. Abroad, I try to understand the host national culture

$\mathrm{CO} 2$. Having many contacts with the nationals of the host country is important when abroad

CO3. Learning about other cultures is interesting and fun.

Social orientation (SO) $(\alpha=.96)$

SO1. It is easy for me to make new friends

SO2. I feel comfortable when I encounter foreigners

SO3. In general, I am comfortable in social settings even when there are lots of people I do not know

Willingness to communicate (WtC) $(\alpha=.94)$

$\mathrm{WtC} 1$. If I were speaking with a foreigner in their native language and they said something important but I did not understand, I would ask them to explain it again

WtC2. Even if I couldn't speak a foreign language well, I would try to use what I knew

WtC3. Even though I make mistakes, I enjoy trying to communicate with foreigners

WtC4. If a foreigner didn't understand what I said, I'd be willing to explain it a couple of different 
times if I needed to.

\section{Confidence in one's technical ability (CTA) $(\alpha=.94)$}

CTA1. My professional skills will enable me to successfully complete my mission in India CTA2. I have the necessary professional competencies for this mission in India CTA3. I am professionally qualified for this job in India

\section{Active stress resistance index (ASR)}

Generally speaking, when you face a stressful situation, how do you react?

Distribute 100 points among the four statements

ASR1. I take action.

-- points

ASR2. I actively seek help or additional information.

-- points

ASR3. I try to see things in a positive light.

-- points

ASR4. I try to forget about the problem and I deal with the consequences of stress. -- points 
Figure 1. Our research model and hypotheses

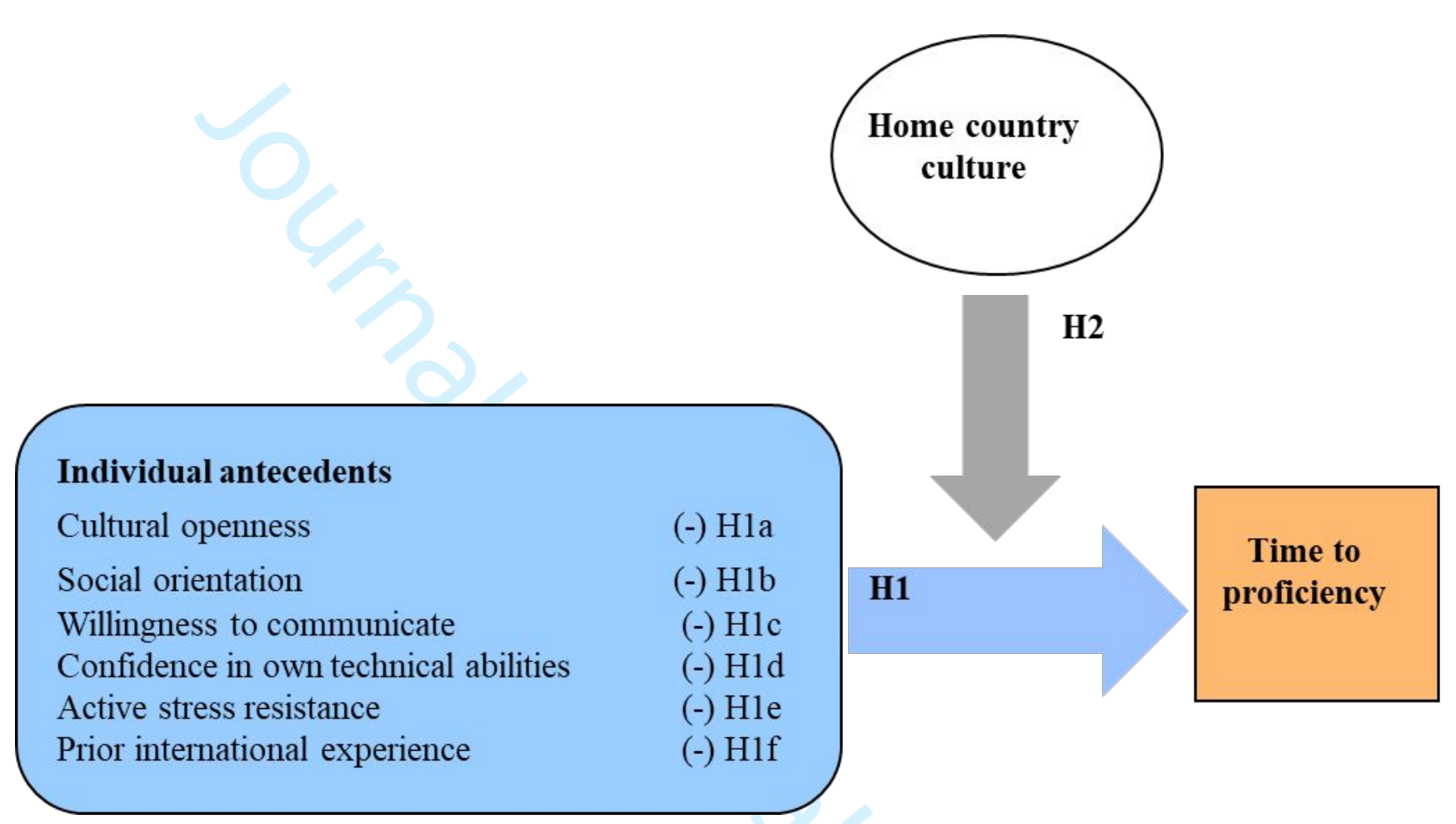


Table 1. Correlations, means and standard deviations of construct measures

\begin{tabular}{|c|c|c|c|c|c|c|c|}
\hline OVERALL SAMPLE & 1. & 2. & 3. & 4. & 5. & 6. & 7. \\
\hline 1. Confidence in technical ability & $(.94)$ & & & & & & \\
\hline 2. Social orientation & $.19^{* *}$ & $(.96)$ & & & & & \\
\hline 3. Willingness to communicate & .10 & $.47^{* *}$ & $(.94)$ & & & & \\
\hline 4. Cultural openness & $.24^{* *}$ & $.19^{* *}$ & $.24^{* *}$ & $(.93)$ & & & \\
\hline 5. Time to proficiency & $-.22^{* *}$ & $-.29^{* *}$ & $-.32^{* *}$ & $-.22^{* *}$ & $(.95)$ & & \\
\hline 6. Active stress resistance & .11 & .08 & .08 & $.20^{* *}$ & $-.24^{* *}$ & & \\
\hline 7. Previous international experience & .02 & .08 & .09 & $.24^{* *}$ & $-.15^{*}$ & $.14^{*}$ & \\
\hline Mean & 5.27 & 4.94 & 5.25 & 4.99 & 17.31 & 58.82 & 2.19 \\
\hline Standard deviation & 1.19 & 1.15 & 1.11 & 1.22 & 8.87 & 21.65 & 2.34 \\
\hline \multicolumn{8}{|l|}{ FRANCE } \\
\hline 1. Confidence in technical ability & $(.93)$ & & & & & & \\
\hline 2. Social orientation & $.18^{* *}$ & $(.97)$ & & & & & \\
\hline 3. Willingness to communicate & .03 & $.45^{* *}$ & $(.96)$ & & & & \\
\hline 4. Cultural openness & $.21^{* *}$ & .07 & $.31^{* *}$ & $(.95)$ & & & \\
\hline 5. Time to proficiency & $-.29^{* *}$ & .01 & $-.11^{*}$ & $-.43^{* *}$ & $(.96)$ & & \\
\hline 6. Active stress resistance & $.28^{* *}$ & $-.11^{*}$ & -.07 & $.26^{* *}$ & $-.45^{* *}$ & & \\
\hline 7. Previous international experience & -.02 & $.25^{* *}$ & $.13^{*}$ & .02 & $-.21^{* *}$ & $.14^{*}$ & \\
\hline Mean & 5.31 & 5.39 & 5.20 & 4.95 & 11.35 & 57.87 & 1.88 \\
\hline Standard deviation & 0.99 & 1.11 & 1.00 & 0.99 & 14.95 & 20.95 & 2.01 \\
\hline \multicolumn{8}{|l|}{ GERMANY } \\
\hline 1. Confidence in technical ability & $(.88)$ & & & & & & \\
\hline 2. Social orientation & $.30^{* *}$ & $(.97)$ & & & & & \\
\hline 3. Willingness to communicate & $.34^{* *}$ & $.42^{* *}$ & $(.96)$ & & & & \\
\hline 4. Cultural openness & $.21^{* *}$ & $.28^{* *}$ & $.34^{* *}$ & $(.91)$ & & & \\
\hline 5. Time to proficiency & $-.31^{* *}$ & $-.21^{* *}$ & $-.32^{* *}$ & -.07 & $(.95)$ & & \\
\hline 6. Active stress resistance & $.20^{* *}$ & $.13^{*}$ & .00 & .03 & $-.29^{* *}$ & & \\
\hline 7. Previous international experience & .01 & .09 & $.20^{* *}$ & $.21^{* *}$ & $-.11^{*}$ & $-.14^{*}$ & \\
\hline Mean & 5.38 & 5.09 & 5.28 & 4.44 & 14.95 & 55.56 & 1.67 \\
\hline Standard deviation & 1.09 & 1.25 & 1.18 & 0.96 & 5.78 & 21.94 & 1.79 \\
\hline \multicolumn{8}{|l|}{ KOREA } \\
\hline 1. Confidence in technical ability & $(.95)$ & & & & & & \\
\hline 2. Social orientation & $.15^{*}$ & $(.95)$ & & 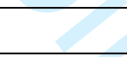 & 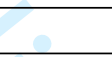 & & \\
\hline 3. Willingness to communicate & $-.14^{*}$ & $.57^{* *}$ & $(.93)$ & + & 8 & & \\
\hline 4. Cultural openness & $.13^{*}$ & $.39^{* *}$ & $.19^{* *}$ & $(.96)$ & 20 & & \\
\hline 5. Time to proficiency & .08 & $-.22^{* *}$ & $-.55^{* *}$ & $-.19^{* *}$ & $(.92)$ & & \\
\hline 6. Active stress resistance & .02 & $.15^{*}$ & $.22^{* *}$ & $.33^{* *}$ & $-.28^{* *}$ & & \\
\hline 7. Previous international experience & .05 & -.03 & $.11^{*}$ & $.24^{* *}$ & $-.28^{* *}$ & $.20^{* *}$ & \\
\hline Mean & 4.89 & 4.60 & 5.12 & 4.69 & 24.90 & 59.41 & 1.72 \\
\hline Standard deviation & 1.36 & 1.11 & 1.22 & 1.19 & 10.50 & 23.18 & 2.06 \\
\hline \multicolumn{8}{|l|}{ SCANDINAVIA } \\
\hline 1. Confidence in technical ability & $(.93)$ & & & & & & \\
\hline 2. Social orientation & $.14^{*}$ & $(.95)$ & & & & & \\
\hline 3. Willingness to communicate & $.23^{* *}$ & $.50^{* *}$ & $(.92)$ & & & & \\
\hline 4. Cultural openness & $.34^{* *}$ & $.19^{* *}$ & $.18^{* *}$ & $(.93)$ & & & \\
\hline 5. Time to proficiency & $-.54^{* *}$ & $-.39^{* *}$ & $-.21^{* *}$ & $-.35^{* *}$ & $(.95)$ & & \\
\hline
\end{tabular}




\begin{tabular}{|l|c|c|c|c|c|c|c|}
\hline 6. Active stress resistance & .04 & $.15^{*}$ & .09 & .06 & $-.29^{* *}$ & 1.00 & \\
\hline 7. Previous international experience & -.07 & $.15^{*}$ & -.08 & $.15^{*}$ & -.07 & $.18^{* *}$ & 1.00 \\
\hline Mean & 5.50 & 4.75 & 5.41 & 5.51 & 17.17 & 62.10 & 3.45 \\
\hline Standard deviation & 1.21 & 0.99 & 1.01 & 1.14 & 5.83 & 20.41 & 2.89 \\
\hline
\end{tabular}

Notes: Cronbach's alpha coefficients $(\alpha)$ are displayed on the diagonal. ${ }^{* *} \mathrm{p}<.01,{ }^{*} \mathrm{p}<.05$

10

11

12

13

14

15

16

17

18

19

20

21

22

23

24

25

26

27

28

29

30

31

32

33

34

35

36

37

38

39

40

41

42

43

44

45

46

47

48

49

50

51

52

53

54

55

56

57

58

59

60 


\section{Table 2. Model validation results}

\begin{tabular}{|c|c|c|c|c|c|c|c|c|c|c|c|c|c|c|c|c|}
\hline 5 & & Over: & $\overline{\text { Sample }}$ & $\mathrm{n}=\mathbf{2 2 4})$ & France & $\mathrm{n}=54)$ & & Germ: & $y(n=5$ & & Korea & $\mathrm{n}=60$ ) & & Scand & avia (n & \\
\hline 6 & Construct and Items & Loading & IC & AVE & Loading & IC & AVE & Loading & IC & VE & Loading & IC & AVE & Loading & IC & AVE \\
\hline $\begin{array}{l}7 \\
8 \\
9\end{array}$ & $\begin{array}{l}\text { Confidence in } \\
\text { technical } \\
\text { ability (CTA) }\end{array}$ & & .96 & .89 & & .97 & .91 & & .95 & .85 & & .97 & .92 & & .96 & .88 \\
\hline 10 & CT1 & .96 & 28 & & .95 & & & .94 & & & .98 & & & .98 & & \\
\hline 11 & CT2 & .93 & a & 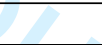 & .96 & & & .94 & & & .95 & & & .88 & & \\
\hline 12 & CT3 & .94 & & +8 & .96 & & & .89 & & & .95 & & & .95 & & \\
\hline $\begin{array}{l}13 \\
14 \\
15\end{array}$ & $\begin{array}{l}\text { Social } \\
\text { orientation } \\
\text { (CO) }\end{array}$ & & .97 & .93 & 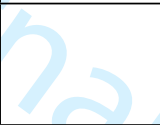 & .98 & .95 & & .98 & .93 & & .97 & .91 & & .97 & .91 \\
\hline 16 & SO1 & .97 & & & .96 & & & .93 & & & .97 & & & .97 & & \\
\hline 17 & $\mathrm{SO} 2$ & .96 & & & .97 & 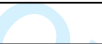 & & .98 & & & .94 & & & .93 & & \\
\hline 18 & $\mathrm{SO} 3$ & .96 & & & .97 & 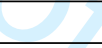 & & .98 & & & .94 & & & .96 & & \\
\hline $\begin{array}{l}19 \\
20 \\
21\end{array}$ & $\begin{array}{l}\text { Willingness to } \\
\text { communicate } \\
\text { (WtC) }\end{array}$ & & .95 & .83 & & .97 & .88 & & .97 & .89 & & .95 & .83 & & .95 & .81 \\
\hline 22 & $\mathrm{WtCl}$ & .93 & & & .95 & & +4 & .96 & & & .94 & & & .95 & & \\
\hline 23 & $\mathrm{WtC2}$ & .91 & & & .93 & & & .93 & & & .90 & & & .90 & & \\
\hline 24 & $\mathrm{WtC} 3$ & .90 & & & .92 & & & .92 & $\overline{0}$ & & .91 & & & .91 & & \\
\hline 25 & WtC4 & .92 & & & .96 & & & .96 & 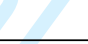 & & .90 & & & .83 & & \\
\hline & $\begin{array}{l}\text { Cultural openness } \\
\text { (CO) }\end{array}$ & & .96 & .88 & & .96 & .88 & & .93 & .81 & & .97 & .91 & & .95 & .87 \\
\hline 28 & $\mathrm{CO} 1$ & .95 & & & .96 & & & .96 & & 8 & .96 & & & .94 & & \\
\hline 29 & $\mathrm{CO} 2$ & .93 & & & .93 & & & .82 & & & .95 & & & .91 & & \\
\hline 30 & $\mathrm{CO} 3$ & .93 & & & .93 & & & .91 & & & .95 & & & .96 & & \\
\hline & $\begin{array}{l}\text { Time to proficiency } \\
\text { (TTP) }\end{array}$ & & .97 & .87 & & .97 & .89 & & .96 & .87 & & .94 & .80 & & .96 & .87 \\
\hline 33 & TTP1 & .93 & & & .96 & & & .91 & & & .89 & D & & .94 & & \\
\hline 34 & TTP2 & .94 & & & .96 & & & .92 & & & .90 & 8 & & .91 & & \\
\hline & TTP3 & .93 & & & .91 & & & .95 & & & .90 & & & .94 & & \\
\hline 36 & TTP4 & .94 & & & .94 & & & .93 & & & 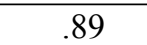 & & & .94 & & \\
\hline
\end{tabular}


Table 3. PLS main effects model results for global sample and home country samples

\begin{tabular}{|c|c|c|c|c|c|c|c|c|c|c|}
\hline \multirow[t]{2}{*}{ Antecedents } & \multicolumn{2}{|c|}{ Global Sample n=224 } & \multicolumn{2}{|c|}{ France $n=54$} & \multicolumn{2}{|c|}{ Germany $n=53$} & \multicolumn{2}{|l|}{ Korea $n=60$} & \multicolumn{2}{|c|}{ Scandinavia $n=57$} \\
\hline & Path Coef. & $t$-value & Path Coef. & $t$-value & Path Coef. & $t$-value & Path Coef. & $t$-value & Path Coef. & $t$-value \\
\hline $\begin{array}{l}\text { Cultural } \\
\text { openness }\end{array}$ & -.05 & $.86 \mathrm{n} . \mathrm{s}$ & -.28 & $2.11 * *$ & .07 & $.47 \mathrm{n} . \mathrm{s}$ & -.07 & $.51 \mathrm{n} . \mathrm{s}$ & -.16 & $1.19 \mathrm{n} . \mathrm{s}$ \\
\hline $\begin{array}{l}\text { Social } \\
\text { orientation }\end{array}$ & -.13 & $1.98 * *$ & .12 & $.77 \mathrm{n} . \mathrm{s}$ & -.02 & $.11 \mathrm{n} . \mathrm{s}$ & .15 & $1.03 \mathrm{n} . \mathrm{s}$ & -.31 & $2.56 * * *$ \\
\hline $\begin{array}{l}\text { Willingness } \\
\text { to } \\
\text { communicate }\end{array}$ & -.21 & $3.05 * * * *$ & -.07 & $.45 \mathrm{n} . \mathrm{s}$ & .25 & $1.80 * *$ & -.58 & $4.65 * * * *$ & .09 & $.64 \mathrm{n} . \mathrm{s}$ \\
\hline $\begin{array}{l}\text { Confidence } \\
\text { in technical } \\
\text { ability }\end{array}$ & -.14 & $2.06 * *$ & -.15 & 1.09 n.s & -.11 & $1.48 \mathrm{n} . \mathrm{s}$ & -.01 & $.08 \mathrm{n} . \mathrm{s}$ & -.46 & $4.46 * * * *$ \\
\hline $\begin{array}{l}\text { Active stress } \\
\text { resistance }\end{array}$ & -.37 & $2.65 * * *$ & -.35 & $3.24 * * * *$ & -.27 & $1.98 * *$ & -.11 & $.89 \mathrm{n} . \mathrm{s}$ & -.25 & $2.50 * * *$ \\
\hline $\begin{array}{l}\text { Previous } \\
\text { international } \\
\text { experience }\end{array}$ & -.08 & $1.42 \mathrm{n} . \mathrm{s}$ & -.18 & $1.84 * *$ & -.11 & $.73 \mathrm{n} . \mathrm{s}$ & -.17 & $1.81 * *$ & .01 & .09 n.s \\
\hline$R^{2}$ & .20 & & .39 & & .21 & & .38 & & .47 & \\
\hline
\end{tabular}

Notes: $* \mathrm{p}$-values: $* * * * \mathrm{p}<.001, * * * \mathrm{p}<.010, * * \mathrm{p}<.05$, n.s not significant 
Table 4. Summary of results: individual antecedents of expatriate time to proficiency on the global and different home country samples

\begin{tabular}{|l|c|c|c|c|c|}
\hline $\begin{array}{l}\text { Antecedents of } \\
\text { expatriate time to } \\
\text { proficiency }\end{array}$ & Flobal & Grance & Kermany & Scandinavia & Korea \\
\hline Cultural openness & $\boldsymbol{V}$ & & & $\boldsymbol{V}$ & \\
\hline $\begin{array}{l}\text { Social orientation } \\
\text { Willingness to } \\
\text { communicate }\end{array}$ & $\boldsymbol{V}$ & $\boldsymbol{V}$ & & $\boldsymbol{V}$ \\
\hline $\begin{array}{l}\text { Confidence in own } \\
\text { technical abilities }\end{array}$ & $\boldsymbol{V}$ & $\boldsymbol{V}$ & $\boldsymbol{V}$ & $\boldsymbol{V}$ & \\
\hline $\begin{array}{l}\text { Active stress } \\
\text { resistance }\end{array}$ & $\boldsymbol{V}$ & $\boldsymbol{V}$ & & & $\boldsymbol{V}$ \\
\hline $\begin{array}{l}\text { Prior international } \\
\text { experience }\end{array}$ & & & & & \\
\hline
\end{tabular}

$V$ : significant negative relationship with expatriate TTP. 